Cartographic Perspectives $(C P)$ publishes original articles demonstrating creative and rigorous research in cartography and geographic visualization under open-source licensing. Papers undergo double-blind peer review; those accepted for publication must meet the highest standards of scholarship, address important research problems and issues, and appeal to a diverse audience.

Articles should be submitted online, in OpenOffice, Microsoft Word, or RTF file format. Each manuscript is reviewed by the editor, one or more members of the editorial board, and at least one external reviewer. By uploading to the $C P$ website, authors agree to not submit the manuscript elsewhere until the $C P$ editor has reached a decision. Any submitted manuscript must not duplicate substantial portions of previously published material.

\section{GENERAL GUIDELINES}

Content should be submitted online via the Cartographic Perspectives website, cartographicperspectives.org.

OPINION/RESPONSE PIECES: CP welcomes topical responses to previously published articles. The length of such pieces may vary; however, we suggest 2,000 words or less as an informal guide.

ILLUSTRATIONS: Maps, graphs, and photos should convey ideas efficiently and tastefully. Graphics should be legible, clean, and clearly referenced by call-outs in the text. Sound principles of design should be employed in the construction of graphic materials, and the results should be visually interesting and attractive.

- All graphics must be in digital form, either digitally generated or scanned. Preferred formats are .tif, .ai, .eps, .jpg, or press-ready .pdf.

- Images must be embedded in the manuscript. Upon acceptance, they must also be sent as separate files.

- Color images should be submitted in CMYK where possible.

- Images in raster format must, at minimum, be $1000 \mathrm{px}$ wide; at least 2000px is strongly preferred. Images will be printed at 300 ppi.

- Where possible, graphics should have a transparent, rather than a white, background.

- Digital art files should be cropped to remove nonprinting borders (such as unnecessary white space around an image).

- The editors the right to make minor adjustments to illustrations.

- Authors are responsible for ensuring that they have permission to use all illustrations.

- Image orientation should be the same as intended for print.
- For vector files, fonts should be embedded or converted to outlines.

- Type sizes below 6 point should be avoided.

- Captions should not be part of the illustration. Instead, please supply captions within the text of the article.

For questions on specific guidelines for graphics, please contact Assistant Editor Daniel Huffman for more information: daniel.p.huffman@gmail.com.

PERMISSIONS: If a manuscript incorporates a substantial amount of previously published material, the author is obliged to obtain written permission from the holder of the copyright and to bear all costs for the right to use copyrighted materials.

LICENSE: Articles submitted to $C P$ will be distributed under the Creative Commons AttributionNonCommercial-NoDerivs 4.0 International license. For a description of the terms of this license, please see: http:// creativecommons.org/licenses/by-nc-nd/4.0/.

\section{PEER-REVIEWED ARTICLES}

TITLE: The title serves as the author's invitation to a diverse audience. It should be chosen wisely. The title section should include the full names of the authors, their email addresses, and their academic or professional affiliations.

ABSTRACT: An abstract of 250 words or less should summarize the purpose, methods, and major findings of the paper.

KEYWORDS: Five to ten keywords should be listed at the end of the abstract.

REFERENCES: References should be cited parenthetically in the text, following the author-date system found in The Chicago Manual of Style, $16^{\text {th }}$ ed. (chicagomanualofstyle. org). When making a direct quote, include the page number. Examples: (Doe 2001) and (Doe 2001, 38). 
Books: Invert the first author's name (last name, first initial or name, and middle initial). Middle initials should be given wherever known. For books with multiple authors, authors' names are listed in the order in which they appear on the title page, with the last author's name preceded by a comma and and. Note: With more than ten authors, invert first author's name and follow it with a comma and the words et al. without italics in the reference list.

The general format is: Name of author(s). Year. Title in Italics. City of Publication: Publisher Name.

\section{Robinson, A. H., J. L. Morrison, P. C. Muehrcke, A. J. Kimerling, and S. C. Guptill. 1995. Elements of Cartography, $6^{t h}$ Edition. New York: John Wiley \& Sons.}

Articles in Periodicals: Author's or authors' names as in Books, above. Year. "Title of Article." Title of Periodical, volume number, page numbers, DOI if available. Follow punctuation and spacing shown in the following example.

Peterson, M. 2008. "Choropleth Google Maps.” Cartographic Perspectives 60: 80-83. doi: 10.14714/ CP60.237.

Articles in edited volumes: Name of author(s). Year. "Title of Article." In Title of Edited Volume, edited by [Editor's or Editors' names, not inverted], page numbers. City of Publication: Publisher's Name.

Danzer, Gerald. 1990. "Bird's-Eye Views of Towns and Cities." In From Sea Charts to Satellite Images: Interpreting North American History through Maps, edited by David Buisseret, 143-163. Chicago: University of Chicago Press.

Websites: Websites may be generally referenced in running text ("On its website, the Evanston Public Library Board of Trustees states...") rather than with a URL listing. For more formal citations, use the following format: Name of author(s). Year. "Title of Document." Title of Complete Work (if relevant). Access date. URL.

Cartography Associates. 2009. "David Rumsey Donates 150,000 Maps to Stanford University." David Rumsey Map Collection. Accessed January 3, 2011. http://www.davidrumsey.com/blog/2009/8/29/ david-rumsey-donates-150-000-maps-to-stanford.
Maps: Maps should be treated similarly to books, to the extent possible. Specific treatment may vary, however, and it is often preferable to list the map title first. Provide sufficient information to clearly identify the document.

\section{A Plan of the City of New York and its Environs. P.}

Andrews, sold by A. Dury in Dukes Court, St.

Martins Lane, surveyed by John Montressor, 1775.

E-mail correspondence: E-mail messages may be cited in running text ("In an e-mail message to the author on October 31, 2005, John Doe revealed...") instead of in a note or an in-text citation, and they are rarely listed in a bibliography or reference list.

Additional examples: For additional examples, please consult The Chicago Manual of Style, $16^{\text {th }}$ ed. (chicagomanualofstyle.org).

DOI NUMBERS: DOI numbers for references must be included whenever available. You can look up DOIs at www. crossref.org/SimpleTextQuery.

REFERENCES LIST: The list of references should begin in a separate section, immediately after the text. Entitle the section "References" and list all references alphabetically by the author's last name, then chronologically. Provide full, unabbreviated titles of books and periodicals.

FOOTNOTES: Footnotes should be used sparingly: i.e., only when substantive enough to amplify arguments in the text. They should be addressed to a single point in the manuscript. Footnotes should be numbered sequentially in the text and will appear at the bottom of the page.

UNITS OF MEASURE: Cartographic Perspectives uses the International System of Units (metric). Other units should be noted in parentheses.

EQUATIONS: Equations should be numbered sequentially and parenthetically on the right-hand edge of the text. If special type styles are required, instructions should be provided in the margin adjoining the first case of usage. Authors should carefully distinguish between capital and lower-case letters, Latin and Greek characters, and letters and numerals.

TABLES: Tables should be discussed in the text and denoted by call-outs therein, but the meaning of a table should be clear without reading the text. Each table should have a descriptive title as well as informational column headings. Titles should accent the relationships or patterns presented in the table. 